\title{
Assessment of orofacial dysfunction in a group of Polish children with unilateral cleft lip and palate: A preliminary report
}

\author{
Natalia Kaczorowska ${ }^{1, A-E}$, Patrycja Markulak ${ }^{2, B, D}$, Marcin Mikulewicz ${ }^{1, F}$ \\ ${ }^{1}$ Department of Dentofacial Orthopedics and Orthodontics, Division of Facial Abnormalities, Wroclaw Medical University, Poland \\ ${ }^{2}$ Department of Dentofacial Orthopedics and Orthodontics, Division of Dentofacial Orthopedics and Orthodontics, Wroclaw Medical University, Poland \\ A - research concept and design; $B$ - collection and/or assembly of data; $C$ - data analysis and interpretation; \\ $D$ - writing the article; $E$ - critical revision of the article; $F$ - final approval of the article
}

\section{Address for correspondence \\ Natalia Kaczorowska \\ E-mail: nataliakaczorowskaa@gmail.com}

Funding sources

None declared

Conflict of interest

None declared

Received on July 26,2020

Reviewed on September 13, 2020

Accepted on 0ctober 6, 2020

\begin{abstract}
Background. Cleft lip and palate (CLP) is a genetic and environmental malformation of the face. The resulting interruption of the tissue in the mouth and nasal cavity undoubtedly impairs basic physiological functions, which impacts the quality of life (Qol) of such patients.

Objectives. To assess orofacial dysfunction using the Nordic Orofacial Test-Screening (NOT-S) in a group of Polish children with unilateral CLP (UCLP). The following hypotheses were presented: 1) orofacial dysfunction is more common in children with UCLP and 2) patients with UCLP have a worse QoL than the control group.
\end{abstract}

Material and methods. Seventy children at the age of 7-13 years took part in the study. The inclusion criterion was a diagnosis of UCLP. The control group (non-UCLP) was matched by gender and age to the cleft group. The research used the NOT-S questionnaire.

Results. In the cleft group, there were statistically significantly more disorders of functions, such as breathing, chewing and swallowing, and drooling; in the NOT-S examination, there were more disorders of the face at rest, facial expression and speech in the cleft group. Comparing the NOT-S total scores, it was found that in the cleft group, there a disorder of at least 1 function was statistically significantly more prevalent than in the control group. Likewise, the median results in the cleft group were 3 points higher than in the control group.

Conclusions. Using the NOT-S survey, it was possible to confirm both hypotheses. Orofacial dysfunction is more common in children with UCLP and this contributes to a worse QoL for them than for children without UCLP.

Key words: quality of life, orthodontics, cleft and lip palate, NOT-S questionnaire
Cite as

Kaczorowska N, Markulak P, Mikulewicz M. Assessment of orofacial dysfunction in a group of Polish children with unilateral cleft lip and palate: A preliminary report. Adv Clin Exp Med. 2020;29(11):1331-1336.

doi:10.17219/acem/128187

DOI

10.17219/acem/128187

Copyright

Copyright by Author(s)

This is an article distributed under the terms of the

Creative Commons Attribution 3.0 Unported (CC BY 3.0)

(https://creativecommons.org/licenses/by/3.0/) 


\section{Introduction}

Cleft lip and palate (CLP) is a genetic and environmental face malformation. ${ }^{1}$ According to WHO data, it occurs once per approx. 1,100 births around the world. ${ }^{2}$ Facial deformities include a disruption of soft and hard tissues, and asymmetry. Scientific studies have shown that asymmetry is present not only in the maxilla, but can also apply to the orbital, zygomatic and frontal bones. ${ }^{3}$ Dental anomalies among these patients include hypodontia, supernumerary teeth, microdontia, taurodontism, and transposition of teeth, ${ }^{4}$ while occlusal disorders are most often cross-bite and class III malocclusion. ${ }^{5}$

There is no doubt that the abovementioned abnormalities affect speech, articulation, chewing, nose function, and facial appearance. ${ }^{6}$ In addition, patients with CLP significantly suffer from otitis media. ${ }^{7}$ Speech disorders of people with CLP include delayed speech development, articulation disorders and dysphonia. Moreover, in some cases, fluid and food refluxes often occur and swallowing is difficult. ${ }^{8}$ However, it should be noted that the negative impact of CLP mainly concerns psychosocial problems. ${ }^{9}$

The amount of research conducted around the world shows that there is an interest in the quality of life (QoL) of patients with CLP. Researchers from Brazil have proven that the effect of CLP on QoL increases with age. ${ }^{10}$ Studies conducted in Iran showed that the biggest difference compared to the control group was in difficulty pronouncing words and that the impact on QoL also concerned the patients' families, emphasizing mainly the financial aspect and parental stress. ${ }^{11}$ A survey of CLP patients in the Netherlands, on the other hand, showed that gender does not affect QoL among this group. ${ }^{12}$ Furthermore, studies in Switzerland involving patients with unilateral CLP (UCLP) showed a worse sleep pattern than in patients without the disorder; it was emphasized, however, that this is not due to CLP, but to psychosocial loads. ${ }^{13}$

Despite the fact that the QoL of people with cleft lips and palates has been studied for many years, there is no standardized test for its assessment. As a result, researchers evaluate various aspects of life and activities in society and use a variety of questions. One such tool is the Nordic Orofacial Test-Screening (NOT-S) survey. ${ }^{14}$ The NOT-S has been used to assess the QoL of people with cleft palates, ${ }^{15}$ cerebral palsy ${ }^{16}$ or ectodermal dysplasia $^{17}$ since 2007.

We conducted a survey among the Polish population to study the QoL of patients with UCLP in comparison with a control group. This is the first study to use the NOT-S questionnaire in Poland.

The following hypotheses were proposed:

1. Orofacial dysfunction is more common in children with UCLP.

2. Patients with UCLP have a worse QoL than the control group.

\section{Material and methods}

\section{Material}

This study was conducted in full accordance with the World Medical Association Declaration of Helsinki and was approved by the Ethics Committee of the Wroclaw Medical University, Poland.

The cleft group $(n=35)$ comprised of patients of the Department of Maxillofacial Orthopedics and Orthodontics of the Division of Facial Abnormalities at the Wroclaw Medical University. The inclusion criteria were a diagnosis of UCLP (diagnosis code Q37.1 of the ICD10) and an age of 7-13 years. The exclusion criteria were mental retardation, being under 7 or over 13 years of age, and missing teeth not related to tooth replacement. The age of the cleft group was between 7 and 13 years. Before conducting the study, legal guardians were informed about it and were assured about the confidentiality of the data of the children.

The control group, without a diagnosis of CLP $(n=35)$ and matched in terms of sex and age to the cleft group, were patients of the Division of Maxillofacial Orthopedics and Orthodontics at the Wroclaw Medical University.

\section{Methods}

The study used the NOT-S survey after it was translated into Polish by the researchers. The children were examined by the same trained examiner according to the same protocol. Each survey contained data on age, gender, diagnostic code (ICD-10), examination position, and position of the head when seated. The interview reflected 6 domains: I) sensory function, II) breathing, III) habits, IV) chewing and swallowing, V) drooling, and VI) dryness of the mouth. The examination contains sections: 1 ) the face at rest and tasks regarding 2) nose breathing, 3) facial expression, 4) masticatory muscle and jaw function, 5) oral motor function, and 6) speech. Each of these domains contains from 1 to 5 components for which the patients' responses or examination results were recorded: $X=$ yes, $0=$ no, or $(-)=$ not assessed. If there was 1 or more $\mathrm{X}$ answers in a section, the researchers placed a score of 1 in the domain. The results were recorded at the time the survey was conducted on pre-printed NOT-S forms. The total possible NOT-S score ranges from 0 to 12 points. The higher the score, the more severe the orofacial dysfunction and the worse the QoL.

\section{Statistical analysis}

Statistical analysis was performed using STATISTICA v. 13 (StatSoft Inc., Tulsa, USA). For measurable variables, the mean, median (Me), upper and lower quartile, and range of variability (extreme values - minimum (Min) and maximum (Max)) were calculated. The frequency 
of occurrence (percent) was calculated for qualitative variables. All quantitative variables were checked with the Shapiro-Wilk test to determine the type of distribution. The qualitative variables between groups (cleft compared to the control) were compared using the two-tailed Fisher's exact test. The quantitative variables between groups were compared using the Mann-Whitney U test. The level of $\alpha=0.05$ was used for all comparisons.

\section{Results}

Table 1 presents a comparison of the frequency of a particular function based on the NOT-S between the cleft group $(n=35)$ and the control group $(n=35)$. The $1^{\text {st }}$ part presents the results from the 6 sections assessed with NOT-S interviews: sensory functions, breathing, habits, chewing and swallowing, drooling, and dryness of the mouth. The $2^{\text {nd }}$ part contains the results from the 6 NOT-S examination sections: face at rest, nose breathing, facial expression, masticatory muscle and jaw function, oral motor function, and speech. The $3^{\text {rd }}$ part is the summary of the entire test (NOT-S total score).

In the NOT-S interview, it was observed that disorders of functions such as breathing, drooling, chewing, and swallowing were statistically significantly more prevalent in the cleft group. In the cleft group, breathing disorders were found in almost $46 \%(n=16)$ of the study participants, while in the control group, this figure was $11.4(n=4$; $\mathrm{p}=0.003$ ). Disorders of the next 2 functions were also more common in the cleft group: disorders of chewing and swallowing function were noted in $51.4 \%$ of patients $(\mathrm{n}=18$ compared to the control group: $8.6 \%$; $n=3$; $p<0.001$ ), and drooling in $25.7 \%$ ( $n=9$ compared to the control group: $2.9 \% ; \mathrm{n}=1 ; \mathrm{p}=0.013$ ). In addition, the summaries of the interview part were compared. The number

Table 1. Comparison of the frequency of selected function disorders based on NOT-S between the cleft group and the control group

\begin{tabular}{|c|c|c|c|c|c|c|}
\hline \multirow{2}{*}{\multicolumn{2}{|c|}{ Nordic Orofacial Test }} & \multicolumn{2}{|c|}{ Cleft group $(n=35)$} & \multicolumn{2}{|c|}{ Control group $(n=35)$} & \multirow{2}{*}{$p$-value* } \\
\hline & & $\mathrm{n}$ & $\%$ & $\mathrm{n}$ & $\%$ & \\
\hline \multicolumn{7}{|c|}{ I. NOT-S interview } \\
\hline Sensory function & $\begin{array}{l}0 \\
1\end{array}$ & $\begin{array}{c}32 \\
3\end{array}$ & $\begin{array}{c}91.4 \\
8.6\end{array}$ & $\begin{array}{c}35 \\
-\end{array}$ & $\begin{array}{c}100 \\
-\end{array}$ & 0.23 \\
\hline Breathing & $\begin{array}{l}0 \\
1\end{array}$ & $\begin{array}{l}19 \\
16\end{array}$ & $\begin{array}{l}54.3 \\
45.7\end{array}$ & $\begin{array}{c}31 \\
4\end{array}$ & $\begin{array}{l}88.6 \\
11.4\end{array}$ & 0.003 \\
\hline Habits & $\begin{array}{l}0 \\
1\end{array}$ & $\begin{array}{l}17 \\
18\end{array}$ & $\begin{array}{l}48.6 \\
51.4\end{array}$ & $\begin{array}{l}25 \\
10\end{array}$ & $\begin{array}{l}71.4 \\
28.6\end{array}$ & 0.087 \\
\hline Chewing and swallowing & $\begin{array}{l}0 \\
1\end{array}$ & $\begin{array}{l}17 \\
18\end{array}$ & $\begin{array}{l}48.6 \\
51.4\end{array}$ & $\begin{array}{c}32 \\
3\end{array}$ & $\begin{array}{c}91.4 \\
8.6\end{array}$ & $<0.001$ \\
\hline Drooling & $\begin{array}{l}0 \\
1\end{array}$ & $\begin{array}{c}26 \\
9\end{array}$ & $\begin{array}{l}74.3 \\
25.7\end{array}$ & $\begin{array}{c}34 \\
1\end{array}$ & $\begin{array}{c}97.1 \\
2.9\end{array}$ & 0.013 \\
\hline Dryness of the mouth & $\begin{array}{l}0 \\
1\end{array}$ & $\begin{array}{l}25 \\
10\end{array}$ & $\begin{array}{l}71.4 \\
28.6\end{array}$ & $\begin{array}{c}32 \\
3\end{array}$ & $\begin{array}{c}91.4 \\
8.6\end{array}$ & 0.062 \\
\hline NOT-S interview - total score & $\begin{array}{c}0 \\
\geq 1\end{array}$ & $\begin{array}{c}2 \\
33\end{array}$ & $\begin{array}{c}5.7 \\
94.3\end{array}$ & $\begin{array}{l}16 \\
19\end{array}$ & $\begin{array}{l}45.7 \\
54.3\end{array}$ & $<0.001$ \\
\hline \multicolumn{7}{|c|}{ II. NOT-S examination } \\
\hline Face at rest & $\begin{array}{l}0 \\
1\end{array}$ & $\begin{array}{l}12 \\
23\end{array}$ & $\begin{array}{l}34.3 \\
65.7\end{array}$ & $\begin{array}{c}31 \\
4\end{array}$ & $\begin{array}{l}88.6 \\
11.4\end{array}$ & $<0.001$ \\
\hline Nose breathing & $\begin{array}{l}0 \\
1\end{array}$ & $\begin{array}{c}32 \\
3\end{array}$ & $\begin{array}{c}91.4 \\
8.6\end{array}$ & $\begin{array}{c}35 \\
-\end{array}$ & $\begin{array}{c}100 \\
-\end{array}$ & 0.24 \\
\hline Facial expression & $\begin{array}{l}0 \\
1\end{array}$ & $\begin{array}{c}5 \\
30\end{array}$ & $\begin{array}{l}14.3 \\
85.7\end{array}$ & $\begin{array}{c}34 \\
1\end{array}$ & $\begin{array}{c}97.1 \\
2.9\end{array}$ & $<0.001$ \\
\hline Masticatory muscle and jaw function & $\begin{array}{l}0 \\
1\end{array}$ & $\begin{array}{c}33 \\
2\end{array}$ & $\begin{array}{c}94.3 \\
5.7\end{array}$ & $\begin{array}{c}35 \\
-\end{array}$ & $\begin{array}{c}100 \\
-\end{array}$ & 0.49 \\
\hline Oral motor function & $\begin{array}{l}0 \\
1\end{array}$ & $\begin{array}{c}33 \\
2\end{array}$ & $\begin{array}{c}94.3 \\
5.7\end{array}$ & $\begin{array}{c}35 \\
-\end{array}$ & $\begin{array}{c}100 \\
-\end{array}$ & 0.49 \\
\hline Speech & $\begin{array}{l}0 \\
1\end{array}$ & $\begin{array}{l}10 \\
25\end{array}$ & $\begin{array}{l}28.6 \\
71.4\end{array}$ & $\begin{array}{c}32 \\
3\end{array}$ & $\begin{array}{c}91.4 \\
8.6\end{array}$ & $<0.001$ \\
\hline NOT-S examination - total score & $\begin{array}{c}0 \\
\geq 1\end{array}$ & $\begin{array}{c}0 \\
35\end{array}$ & $\begin{array}{c}0 \\
100\end{array}$ & $\begin{array}{c}27 \\
8\end{array}$ & $\begin{array}{l}77.1 \\
22.9\end{array}$ & $<0.001$ \\
\hline \multicolumn{7}{|c|}{ III. NOT-S - Total score } \\
\hline Total score & $\begin{array}{c}0 \\
\geq 1\end{array}$ & $\begin{array}{c}0 \\
35\end{array}$ & $\begin{array}{c}0 \\
100\end{array}$ & $\begin{array}{l}11 \\
24\end{array}$ & $\begin{array}{l}31.4 \\
68.6\end{array}$ & $<0.001$ \\
\hline
\end{tabular}

NOT-S - Nordic Orofacial Test-Screening; 0 - non-affected; 1 - affected; $\mathrm{n}$ - number of participants; * two-tailed Fisher's exact test. 
Table 2. Comparison of the total results of NOT-S between the cleft group and the control group

\begin{tabular}{|c|c|c|c|c|c|c|c|c|c|c|c|}
\hline \multirow{2}{*}{ Nordic Orofacial Test } & \multicolumn{5}{|c|}{ Cleft group $(n=35)$} & \multicolumn{5}{|c|}{ Control group $(n=35)$} & \multirow{2}{*}{$p$-value* } \\
\hline & $\mathrm{Me}$ & Q1 & Q3 & Min & $\operatorname{Max}$ & Me & Q1 & Q3 & Min & $\operatorname{Max}$ & \\
\hline NOT-S interview - total score & 2 & 1 & 3 & 0 & 5 & 1 & 0 & 1 & 0 & 2 & $<0.001$ \\
\hline NOT-S examination - total score & 2 & 2 & 3 & 1 & 4 & 0 & 0 & 0 & 0 & 1 & $<0.001$ \\
\hline NOT-S - Total score & 4 & 4 & 5 & 2 & 8 & 1 & 0 & 1 & 0 & 2 & $<0.001$ \\
\hline
\end{tabular}

NOT-S - Nordic Orofacial Test-Screening; Me - median; Q1 - lower quartile; Q3 - upper quartile; Min - minimum value; Max - maximum value; *Mann-Whitney U test.

of participants with a disorder of at least 1 function was also listed. There was a disorder of at least 1 function statistically significantly more often in the cleft group than in the control group ( $94.3 \%$ compared to $54.3 \%$; $\mathrm{p}<0.001$ ).

In the NOT-S examination, it was observed that in the cleft group, there were statistically significantly more disorders of functions such as face at rest, facial expression and speech. In the cleft group, facial disorders at rest were found in almost $66 \%(n=23)$ of the study participants, while in the control group, it was $11.4 \%$ ( $n=4$; $\mathrm{p}<0.001$ ). Disorders of the 2 other functions were also more common in participants from the cleft group. In the cleft group, facial expression disorders occurred in $85.7 \%$ ( $n=30$ compared to the control group: $2.9 \%$; $\mathrm{n}=1 ; \mathrm{p}<0.001)$ and speech disorders in $71.4 \%(\mathrm{n}=25$ compared to the control group: $8.6 \% ; \mathrm{n}=3$; $\mathrm{p}<0.001$ ). In addition, the summary results of the NOT-S examination were also compared. In the cleft group, there were statistically significantly more disorders of at least 1 function than in the control group (100\% compared to $22.9 \%$; $\mathrm{p}<0.001)$.Comparing the total score, it was also found that in the cleft group there were statistically significantly more disorders of at least 1 function than in the control group $(100 \%$ compared to $68.6 \%$; $<<0.001)$.

A comparison of the results of the NOT-S between the cleft group $(\mathrm{n}=35)$ and the control group $(\mathrm{n}=35)$ is presented in Table 2. The summary of the NOT-S interview results, the NOT-S examination and the NOT-S total score showed statistically significantly higher values in the cleft group than in the control group. In the cleft group, the Me of the NOT-S interview scores was 2 points, the Min was 0 points and the Max was 5 points (compared to the control group: $\mathrm{Me}=1$ point, $\mathrm{Min}=0, \operatorname{Max}=2$; $\mathrm{p}<0.001)$. The Me in the NOT-S examination total score was 2 points, $(\mathrm{Min}=1, \mathrm{Max}=4$; compared to the control group: $\mathrm{Me}=0 ; \mathrm{p}<0.001)$. Comparing the NOT-S total score, it was also found that Me values in the cleft group were 3 points higher than in the control group $(\mathrm{p}<0.001)$.

\section{Discussion}

This is the first study among the Polish population to use the NOT-S questionnaire. The questionnaire was conducted to assess orofacial dysfunction in children with
UCLP in comparison with the control group. Both hypotheses have been confirmed.

Disorders in the cleft group mainly concerned breathing, chewing and swallowing, drooling, face at rest, facial expression, and speech. These results are consistent with data published by Hairfield et al., ${ }^{18}$ who showed that people with UCLP statistically more often have respiratory problems. This may be directly due to the narrowing of the upper respiratory tract within the nasal cavity among patients with UCLP. ${ }^{19}$ However, it is worth emphasizing that the paranasal sinuses remain well-developed. ${ }^{20}$ Respiratory plethysmography in combination with an integrated pneumotachograph, to measure the percentage of nasal breathing, and a flow pressure test showed that most people had less than $0.4 \mathrm{~cm}^{2}$ of airway, which is less than normal. ${ }^{21}$

Chewing and swallowing disorders affect $51.4 \%$ of the cleft group $(\mathrm{n}=18$; compared to the control group: 8.6\%; $\mathrm{n}=3 ; \mathrm{p}<0.001)$. Using a chewable test material, the particle size of the crushed food was determined in patients with UCLP; it was found to be larger in the cleft group than the control group. Likewise, the number of chewing cycles needed to crush the material was greater. ${ }^{22}$ It is worth emphasizing that the orbicularis oris muscle tension measured with an electromyograph ${ }^{23}$ was higher in the group of patients with UCLP than in the control group while swallowing and at rest.

On the other hand, the results regarding dryness of the mouth show that in the group with UCLP the problem was not statistically significantly more frequent. This confirms a study published in $2008,{ }^{24}$ in which sialometers and sialochemistry were used to assess these patients. There were no differences in the abovementioned parameters between patients with UCLP and those in the control group. Interestingly, cortisol ${ }^{25}$ concentration in the saliva of UCLP patients was also checked as an expression of stress response to determine health-related quality of life (HRQoL). There was no difference in salivary cortisol levels between the patient and control groups. No correlation between cortisol concentration and HRQoL was confirmed.

In the NOT-S examination, facial disorders at rest affected $66 \%(n=23)$ of patients, while in the control group, this figure was $11.4 \%(\mathrm{n}=4 ; \mathrm{p}<0.001)$. It has been shown that the face of patients with CLP is perceived more 
negatively than that of people without the disorder. Moreover, observation of the nose and mouth area in these people lasts longer. It has also been shown that patients with CLP looking at other people with CLP spend more time looking at the nose and less time looking at the eyes than people without CLP. ${ }^{26}$ It should also be emphasized that the intensity of asymmetry increases with a maximum smile. ${ }^{27}$ Based on scientific reports, presurgical nasal molding improves the esthetics of the nose in patients with unilateral clefts of the lip, alveolus and palate, and distinctly flattens nasal wings. ${ }^{28}$

Patients with CLP undergo surgery due to the lack of tissue continuity. However, despite a significant improvement in facial symmetry after surgery, 4 years after surgery the remaining asymmetry is more visible: the philtrum of the upper lip is deviated toward the scar tissue on the cleft side, and the asymmetry of the nose is significantly worse. ${ }^{29}$ The effects of secondary osteotomy were also compared. No significant influence was demonstrated on craniofacial growth in children with UCLP. ${ }^{30}$

Considering the aspects discussed above, it is understandable that they affect the QoL of patients with UCLP, which was confirmed in our study.

\section{Conclusions}

The NOT-S survey is an effective tool for assessing disorders in patients with UCLP. It has been shown that patients with UCLP have more orofacial dysfunctions and worse QoL compared to the control group. Orofacial function areas and treatment outcomes need to be continually evaluated and monitored.

\section{ORCID iDs}

Natalia Kaczorowska 니 https://orcid.org/0000-0003-4270-6143 Patrycja Markulak (1) https://orcid.org/0000-0002-9603-5894 Marcin Mikulewicz (1) https://orcid.org/0000-0001-5754-0284

\section{References}

1. Worley ML, Patel KG, Kilpatrick LA. Cleft lip and palate. Clin Perinatol. 2018;45(4):661-678. doi:10.1016/j.clp.2018.07.006

2. Mossey P, Castilla E. Global Registry and Database on Craniofacial Anomalies. Report of a WHO Registry Meeting on Craniofacial Anomalies. Baurú, Brazil: World Health Organization; 2001.

3. Harikrishnan $P$, Balakumaran V. Analysis of intramaxillary and midface skeletal asymmetry in a three-dimensional model with complete unilateral cleft lip and palate. J Craniofac Surg. 2018;29(8):759762. doi:10.1097/SCS.0000000000004718

4. Al-Jamal GA, Hazza'a AM, Rawashdeh MA. Prevalence of dental anomalies in a population of cleft lip and palate patients. Cleft Palate Craniofac J. 2010;47(4):413-420. doi:10.1597/08-275.1

5. Paradowska-Stolarz A, Kawala B. Occlusal disorder among patients with total clefts of lip, alveolar bone and palate. Biomed Res Int. 2004; 2014:583416. doi:10.1155/2014/583416

6. Van Lierde KM, Dhaeseleer E, Luyten A, Van De Woestijne K, Vermeersch $\mathrm{H}$, Roche N. Parent and child ratings of satisfaction with speech and facial appearance in Flemish pre-pubescent boys and girls with unilateral cleft lip and palate. Int J Oral Maxillofac Surg. 2012 41(2):192-199. doi:10.1016/j.ijom.2011.10.030
7. Sharma RN, Nanda V. Problems of middle ear and hearing in cleft children. Indian J Plast Surg. 2009;42(3):144-148. doi:10.4103/09700358.57198

8. Hirschberg J. Functional consequences of cleft palate and its management [in Hungarian]. Orv Hetil. 2001;142(24):1259-1263.

9. Queiroz Herkrath AP, Herkrath FJ, Rebelo MA, Vettore MV. Measurement of health-related and oral health-related quality of life among individuals with nonsyndromic orofacial clefts: A systematic review and meta-analysis. Cleft Palate Craniofac J. 2015;52(2):157-172. doi:10.1597/13-104

10. Rando GM, Jorge PK, Vitor LLR et al. Oral health-related quality of life of children with oral clefts and their families. J Appl Oral Sci. 2018;26: e20170106. doi:10.1590/1678-7757-2017-0106

11. Zeraatkar M, Ajami S, Nadjmi N, Golkari A. Impact of oral clefts on the oral health-related quality of life of preschool children and their parents. Niger J Clin Pract. 2018;21(9):1158-1163. doi:10.4103/njcp. njcp_426_17

12. Bos $A$, Prahl C. Oral health-related quality of life in Dutch children with cleft lip and/or palate. Angle Orthod. 2011;81(5):865-871. doi:10. 2319/070110-365.1

13. Brand S, Blechschmidt A, Müller A, Sader R, Schwenzer-Zimmerer K, Zeilhofer HF, Holsboer-Trachsler E. Psychosocial functioning and sleep patterns in children and adolescents with cleft lip and palate (CLP) compared with healthy controls. Cleft Palate Craniofac J. 2009; 46(2):124-135. doi:10.1597/07-165.1

14. Bakke M, Bergendal B, McAllister A, Sjögreen L, Asten P. Development and evaluation of a comprehensive screening for orofacial dysfunction. Swed Dent J. 2007;31(2):75-84.

15. Montes ABM, Oliveira TM, Gavião MBD, Barbosa TS. Orofacial functions and quality of life in children with unilateral cleft lip and palate. Braz Oral Res. 2019;33:e0061. doi:10.1590/1807-3107bor-2019. vol33.0061

16. Alaçam A, Çalık Yılmaz BC, Incioğlu AS. Assessment of orofacial dysfunction using the NOT-S method in a group of Turkish children with cerebral palsy. Eur Arch Paediatr Dent. 2019;21(2):215-221. doi:10.1007/ s40368-019-00475-z

17. Bergendal B, McAllister A, Stecksén-Blicks C. Orofacial dysfunction in ectodermal dysplasias measured using the Nordic Orofacial TestScreening protocol. Acta Odontol Scand. 2009;67(6):377-381. doi:10. 1080/00016350903160571

18. Hairfield WM, Warren DW, Seaton DL. Prevalence of mouth breathing in cleft lip and palate. Cleft Palate J. 1988;25(2):135-138.

19. Liu H, Warren DW, Drake AF, Davis JU. Is nasal airway size a marker for susceptibility toward clefting? Cleft Palate Craniofac J. 1992;29(4): 336-339. doi:10.1597/1545-1569_1992_029_0336 inasam_2.3.co_2

20. Koppe T, Weigel C, Bärenklau M, Kaduk W, Bayerlein T, Gedrange T. Maxillary sinus pneumatization of an adult skull with an untreated bilateral cleft palate. J Craniomaxillofac Surg. 2006;34(Suppl 2):91-95. doi:10.1016/S1010-5182(06)60020-6

21. Warren DW, Hairfield WM, Dalston ET. The relationship between nasal airway size and nasal-oral breathing in cleft lip and palate. Cleft Palate J. 1990;27(1):46-52. doi:10.1597/1545-1569(1990)027<0046: trbnas $>2.3 . \mathrm{co} ; 2$

22. Montes ABM, de Oliveira TM, Gavião MBD, de Souza Barbosa T. Occlusal, chewing, and tasting characteristics associated with orofacial dysfunctions in children with unilateral cleft lip and palate: A casecontrol study. Clin Oral Investig. 2018;22(2):941-950. doi:10.1007/ s00784-017-2173-4

23. Ravera MJ, Miralles R, Santander H, Valenzuela S, Villaneuva P, Zúñiga C. Comparative study between children with and without cleft lip and cleft palate, part 2: Electromyographic analysis. Cleft Palate Craniofac J. 2000;37(3):286-291.doi:10.1597/1545-1569_2000_037_0286_csbcwa_ 2.3.co_2

24. Aizenbud D, Peri-Front Y, Nagler RM. Salivary analysis and antioxidants in cleft lip and palate children. Arch Oral Biol. 2008;53(6):517-522. doi:10.1016/j. archoralbio.2007.12.006

25. Sundell AL, Marcusson A, Törnhage CJ. Salivary cortisol rhythms in children with cleft lip and/or palate: A case-control study. Cleft Palate Craniofac J. 2018;55(8):1072-1080. doi:10.1177/1055665618767425

26. Meyer-Marcotty $P$, Gerdes AB, Reuther T, Stellzig-Eisenhauer A, Alpers GW. Persons with cleft lip and palate are looked at differently. J Dent Res. 2010;89(4):400-404. doi:10.1177/0022034509359488 
27. Al Rudainy D, Ju X, Mehendale F, Ayoub A. The effect of facial expression on facial symmetry in surgically managed unilateral cleft lip and palate patients (UCLP). J Plast Reconstr Aesthet Surg. 2019;72(2):273-280. doi:10.1016/j. bjps.2018.10.004

28. Kirbschus A, Gesch D, Heinrich A, Gedrange T. Presurgical nasoalveolar molding in patients with unilateral clefts of lip, alveolus and palate: Case study and review of the literature. J Craniomaxillofac Surg. 2006; 34(Suppl 2):45-48. doi:10.1016/S1010-5182(06)60010-3
29. Al Rudainy D, Ju X, Mehendale FV, Ayoub A. Longitudinal 3D assessment of facial asymmetry in unilateral cleft lip and palate. Cleft Palate Craniofac J. 2019;56(4):495-501. doi:10.1177/1055665618780108

30. Gesch D, Kirbschus A, Mack F, Gedrange T. Comparison of craniofacial morphology in patients with unilateral cleft lip, alveolus and palate with and without secondary osteoplasty. J Craniomaxillofac Surg. 2006;34(Suppl 2):62-66. doi:10.1016/S1010-5182(06)60014-0 